\title{
Design, manufacturing and performance evaluation of house hold gasifier stove: A case study of Ethiopia
}

\author{
Dessie Tarekegn Bantelay ${ }^{1}$, Nigus Gabbiye ${ }^{2}$ \\ ${ }^{1}$ School of Mechanical \& Industrial Engineering, Bahir Dar Institute of Technology, Bahir Dar, 26, Ethiopia \\ ${ }^{2}$ School of Food \& Chemical Engineering, Bahir Dar Institute of Technology, Bahir Dar, 26, Ethiopia
}

Email address:

dessie2000ec@gmail.com (D. T. Bantelay),nigushabtu@gmail.com (N. Gabbiye)

To cite this article:

Dessie Tarekegn Bantelay, Nigus Gabbiye. Design, Manufacturing and Performance Evaluation of House Hold Gasifier Stove: A Case Study of Ethiopia. American Journal of Energy Engineering. Vol. 2, No. 4, 2014, pp. 96-102. doi: 10.11648/j.ajee.20140204.12

\begin{abstract}
Biomass energy accounts for about 11\% of the global primary energy supply, and it is estimated that about 2 billion people worldwide depend on biomass for their energy needs. Yet, most of the use of biomass is in an inefficient manner, primarily in developing countries, leading to a host of adverse implications on human health, environment, workplace conditions, and social wellbeing. Therefore, the utilization of biomass in a clean and efficient manner to deliver modern energy services to the world's poor remains an imperative for the development of community. One possible approach to do this is through the use of efficient biomass gasifiers. Although significant efforts have been directed towards developing and deploying biomass gasifiers in many countries, in Ethiopia especially the gasifiers have technical and economic barriers that hinder house hold gasifier dissemination and application. House hold gasifier stove design, manufacture and scaling up their dissemination remains an elusive goal. This article focuses on identification and evaluation of technical and economical limitations of house hold biomass gasifier stoves manufactured and distributed in Ethiopia. Then designing a family size standard gasifier stove and manufacture and evaluate the performance efficiency of the newly designed house hold gasifier stove. Finally device a mechanism that can improve the overall efficiency and applicability of house hold sized gasifier stoves.
\end{abstract}

Keywords: House Hold Gasifier Stove, Stove Design, Gasifier Stove Limitation, Improved Gasifier Stove

\section{Introduction}

Ethiopia is one of the developing countries with a high level of household energy consumption ${ }^{[1]}$. This consumption is primarily satisfied through excessive burning of biomass ${ }^{[1,}$

2]. The biomass consumption has vast implications both for deterioration of natural resources and the work load of rural women and girls charged with the responsibility of cooking in the kitchen ${ }^{[2]}$.

The use of renewable energy sources in an efficient way are important indicator of a sustainable and environmental friendly energy supply. In Ethiopia still there is no access to adequate energy for their basic needs but the biomass, the primary energy source of the country, is used in a very inefficient way ${ }^{[3]}$. On one hand still Ethiopians do not have access to adequate energy for their basic needs ${ }^{[3]}$. On the other hand a large amount of energy is wasted by using enormous amount biomass fuel in a wasteful manner. The poor combustion technology of traditional stoves has serious negative impact on the health of rural women and small children as cooking traditionally takes place inside houses with very poor ventilation. This aggravated by a high population growth ${ }^{[4]}$.

In Ethiopia still approximately $70-80 \%$ of the primary energy share is taken from biomass ${ }^{[4]}$. But the biomass, basically fuel wood which is directly used or processed to charcoal, neither cultivated in a sustainable way nor it is used efficiently contributing mainly for deforestation. In Ethiopia land degradation is the major cause of agricultural stagnation and poverty ${ }^{[5]}$. Deforestation, accelerated soil erosion, and land degradation are serious problems in Ethiopia ${ }^{[6]}$. Soil degradation is thus the most immediate environmental problem facing the country. The loss of soil and the deterioration in fertility, moisture storage capacity, and structure of the remaining soils all reduce the country's agricultural productivity ${ }^{[7]}$. Therefore, In Ethiopia improving energy efficiency can be seen as a further and a very important dimension to be addressed in the feature work. 


\section{Factors Affecting Gasification Process}

Studies have shown that there are several factors influencing the gasification of wood ${ }^{[8,9,18]}$. These include:

Energy content of Fuel: Fuel with high energy content provides easier combustion to sustain the endothermic gasification reactions. Beech wood chips have an energy content of approximately $20 \mathrm{MJ} / \mathrm{kg}$. This is typical for most biomass sources and has been proved to be easy to gasify ${ }^{[8]}$.

Fuel Moisture content of fuel: Since moisture is a nonburnable component in the biomass, it is important to keep as minimum as possible. All water in the feed stock must be vaporized in the drying phase before combustion. Otherwise there will be difficulty in sustaining combustion because the heat released will be used to evaporate moisture.

Wood with low moisture content can therefore be more readily gasified than that with high moisture. Wood with high moisture content should be dried first before it can be used as fuel for the gasifier. The beech wood chips used in the experiments have been factory dried to a moisture content of $10 \%$ prior to packaging. This makes it suitable as a fuel for the gasifier. Updraft gasifiers are also capable of operating with fuels that have moisture contents of up to $50 \%{ }^{[8,9]}$.

Size of the Fuel: Fuel should be of a form that will not lead to bridging within the reactor. Bridging occurs when unscreened fuels do not flow freely axially downwards in the gasifier. Therefore particle size is an important parameter in biomass gasification because it determines the bed porosity and thus the fluid-dynamic characteristics of the bed. On the other hand, fine grained fuels lead to substantial pressure drops in fixed bed reactors. The experimental wood chips are approximately 7.7 to $38 \mathrm{~mm}^{3}$ and regular in shape ${ }^{[8,9]}$. This size is not fine grained when compared to the micron scale and thus no substantial pressure drops occur in the reactor.

Temperature of the Reactor: There is a need to properly insulate the reactor so that heat losses are reduced. If heat losses are higher than the heat requirement of the endothermic reactions, the gasification reactions will not occur ${ }^{[8]}$.The reactor should be insulated to keep heat losses minimal ${ }^{[10]}$. As the temperature increases the formation of combustible gases will increase and the yield of char and liquids will increase and leads to more complete conversion of the fuel. Hydrocarbon gases (especially methane and ethylene) increase with temperature while the yields of higher hydrocarbons $\left(\mathrm{C}_{3}-\mathrm{C}_{8}\right.$ : organic chemicals having 3 to 8 carbons) decrease at temperatures above $1202^{\circ} \mathrm{F}$. The energy content of the syngas increases steadily up to $1292^{\circ} \mathrm{F}$ then decreases at higher temperatures. The rate of char gasification and yields of methane increase with increasing pressure, and the impacts are most significant at high temperatures $\left(1652^{\circ}-1742^{\circ} \mathrm{F}\right)^{[9]}$

Residence Time: For a given reactor temperature, higher fuel bed heights increase the time fuels are available for reactions to occur (residence time), which increases total syngas yields and increases the concentrations of hydrogen, carbon monoxide, carbon dioxide, methane and ethylene in the syngas.
Fluidization velocity: fluidization is the processing technique employing a suspension of a small solid particle in a vertically rising stream of fluid - usually gas - so that fluid and solid come into intimate contact affects the mixing of particles within the reactor. Higher velocities increase the temperature of the fuel bed and lead to the production of lower energy syngas.

The equivalence ratio: actual fuel-to-air ratio divided by the stoichiometric fuel-to-air ratio affects the temperature of the fuel bed. High ratios increase the rate of syngas production, and low ratios result in the production of lower syngas yields and energy content and more tar. As the steamto-air ratio increases the energy content of the syngas also Increases.

\section{Methods}

After different gasifier stoves collected from end user and manufacturers their technical and economical limitations were assessed thoroughly. The new standard gasifier stove were designed by determining each design parameter as following And each design parameters were computed using the following equations.

Energy demand: This refers to the amount of heat that needs to be supplied by the stove. It was determined based on the amount of food to be cooked and /or water to be boiled and their corresponding specific heat energy. The amount of energy needed to cook food was calculated using equation $3: 1^{[9]}$.

$$
Q_{n}=\frac{M_{f} \times E_{s}}{T}
$$

Where:

$\mathrm{Q}$ - energy needed, $\mathrm{kJ} / \mathrm{hr}$

n

$\mathrm{M}$ - mass of food, $\mathrm{kg}$

$\mathrm{E}_{\mathrm{S}}^{\mathrm{f}}$ - specific energy, $\mathrm{kJ} / \mathrm{kg}$

$\mathrm{T}$ - Cooking time, $\mathrm{hr}$

Energy input: This refers to the amount of energy needed in terms of fuel to be fed into the stove and computed using the formula ${ }^{[9]}$.

$$
F C R=\frac{Q_{n}}{H V_{f} \times \xi_{g}}
$$

Where:

FCR - fuel consumption rate, $\mathrm{kg} / \mathrm{hr}$

$\mathrm{Q}$ - heat energy needed, $\mathrm{kJ} / \mathrm{hr}$

$\mathrm{HV}$ - heating value of fuel, $\mathrm{kJ} / \mathrm{kg}$

$\xi$ - gasifier stove efficiency, $\%$

Reactor diameter: This refers to the size of the reactor and a function of fuel consumed per unit time (FCR) to the specific gasification rate (SGR) of biomass material, which is in the range of 110 to $210 \mathrm{~kg} / \mathrm{m}^{2}-\mathrm{hr}$ as revealed by the results of several test on biomass material gas stoves ${ }^{[9]}$. As shown 
below, the reactor diameter computed using equation $3: 3^{[9]}$.

$$
D=\left(\frac{1.27 \times F C R}{S G R}\right)^{0.5}
$$

Where:

$\mathrm{D}$ - Diameter of reactor, $\mathrm{m}$

FCR - fuel consumption rate, $\mathrm{kg} / \mathrm{hr}$

SGR - specific gasification rate of biomass material, 50$210 \mathrm{~kg} / \mathrm{m}-\mathrm{hr}$

Height of the reactor: This refers to the total distance from the top to bottom end of the reactor. This determines how long would the stove be operated in on loading of fuel. Basically, it is a function of a number of variables such as the required time to operate the gasifier $(\mathrm{T})$, the specific gasification rate (SGR) and the density of biomass material ( $\rho)$. It empirical calculated using equation $3: 4^{[9]}$.

$$
H=\left(\frac{S G R \times T}{\rho}\right)
$$

Where:

$\mathrm{H}$ - Length of the reactor, $\mathrm{m}$

SGR - specific gasification rate of biomass, $\mathrm{kg} / \mathrm{m} 2 \mathrm{-hr}$

$\mathrm{T}$ - Time required to consume biomass, $\mathrm{hr}$

$\rho$ - Biomass material density, $\mathrm{kg} / \mathrm{m}^{3}$

Time to consume biomass: This refers to the total time required to completely gasify the biomass material inside the reactor. This includes the time to ignite the fuel and the time to generate gas, plus the time to completely burn all the fuel in the reactor. The density of the biomass material $(\rho)$, the volume of the reactor ( $\mathrm{Vr})$, and the fuel consumption rate (FCR) are the factors used in determining the total time to consume the biomass material fuel in the reactor. As shown below it was computed using equation 3:5 ${ }^{[9]}$.

$$
T=\frac{\rho \times V_{r}}{F C R}
$$

Where:

$\mathrm{T}$ - Time required for consuming the biomass, $\mathrm{hr}$

$\mathrm{V}_{\mathrm{r}}$ - volume of the reactor, $\mathrm{m}^{3}$

$\rho$ - Biomass material density, $\mathrm{kg} / \mathrm{m}^{3}$

FCR - rate of consumption of biomass material, $\mathrm{kg} / \mathrm{hr}$

Economical insulation thickness: it is the minimum insulation thickness of the stove and computed using equation $3: 6^{[9]}$.

$$
\begin{aligned}
& 2 \pi \mathrm{L}\left(\mathrm{T}_{\mathrm{o}}-\mathrm{T}_{\mathrm{i}}\right)\left(1 / \mathrm{kr}_{\mathrm{o}}-1 / \mathrm{kr}_{\mathrm{o}}^{2}\right)=\left[\left(\ln \left(\mathrm{r}_{\mathrm{o}} / \mathrm{r}_{\mathrm{i}}\right)\right) / \mathrm{k}+\ln \left(\mathrm{r}_{\mathrm{o}} \mathrm{h}_{\mathrm{o}}\right)\right]^{2} \\
& \text { Where: } \\
& \mathrm{L}-\text { Reactor height, } \mathrm{m} \\
& \mathrm{K}-\text { Thermal conductivity of insulation material, } \mathrm{J} / \mathrm{m} \\
& \mathrm{h}-\text { Convective heat transfer, } \mathrm{J} / \mathrm{m}^{2} \\
& \mathrm{~T}_{\mathrm{i}} \text { - insulation's inside temperature, } \mathrm{k} \\
& \text { To - insulation's outside temperature, } \mathrm{k} \\
& \mathrm{r}_{\mathrm{i}} \text { - insulation's inside radius, } \mathrm{m}
\end{aligned}
$$

$$
r_{o}-\text { insulation's outside radius, } m
$$

\section{Results and Discussion}

\subsection{Limitations}

Like other developing countries, In Ethiopia most of the people cook using Biomass fuel by direct combustion and inefficient wood stoves. This causes high waste of wood, health problems and destruction of forest. In the last few decades, many improved wood stoves have been developed but the stoves are;

- Often more difficult to manufacture,

- Often more heat goes to the stove than to the food,

- Do not offer good control of cooking rate, Too short chimney

- Too long chimney

- Poorly insulated chimney and combustion chamber

- Narrow Primary air opening

- Unbalanced Secondary air opening

- Using mild steel for combustion chamber

- Expensive and they are not always accepted by the cooks for whom they are developed.

- Does not consider the traditional cooking method.

Because of these limitations, people often preferred to cook by direct combustion of wood on three stone based combustion process and over charcoal. However, it is very wasteful and very polluting that needs urgent solution. Designing standard house hold gasifier stove that can solve the above limitation and improve manufacturing difficulty, reduce heat lose, having controlled cooking rate, acceptable by user and Operated indoors at economical price was the focus of this work.

\subsection{Design Principles}

In order to improve the overall efficiency and applicability of house hold biomass gasifier stoves to alleviate the prescribed limitations listed above is a must. These can be achieved through

1 Use of locally available raw material

2 Simplify the manufacturing process and reduce the cost of production

3 Offers good control of cooking rate

4 Reduces heat loss to the surrounding during operation

5 Improve indoor air quality

6 Lead to the development of local skills and jobs

7 Improve performance efficiency through

Place an insulated short chimney right above the fire: The combustion chamber chimney will have proportional height. Placing a short chimney above the fire increases draft and helps the fire burn hot and violent. Smoke will contact flame in the chimney and combust, reducing emissions. A taller combustion chamber chimney will clean up more smoke, but a shorter chimney will bring hotter gases to the pot. The very tall combustion chamber chimney can develop too much draft bringing in too much cold air that will decrease heat transfer. So a careful analysis using appropriate software 
packages like Fluent is necessary ${ }^{[1]}$.

The opening into the fire: the size of the spaces within the stove through which hot air flows, and the chimney should all be about the same size. This is called maintaining constant cross sectional area, and helps to keep good draft throughout the stove. Good draft not only keeps the fire hot; it is also essential so that the hot air created by the fire can effectively transfer its heat into the pot. Air does not carry very much energy, so a lot of it needs to go through the stove in order to accomplish the task of heating food or water. The size of the openings is larger in more powerful stoves that burn more wood and make more heat. So to design appropriate cross sectional area throughout the stove it is better to use Catia software.

Insulate the heat flow path: Using insulative materials in the stove design and manufacturing keeps the flue gases hot so that they can more effectively heat the pot. Insulation is full of air holes and is very light. Dense materials are not insulation they soak up heat and divert it from cooking food. The economical thickness of insulation (ETI) is defined as the thickness of insulation for which the cost of insulation is balanced by increased energy savings over the life of the project.

Maximize heat transfer to the pot with properly sized gaps: Getting heat into pots is best done with small channels. The hot flue gases from the fire are forced through these narrow channels, or gaps, where it is forced to scrape against the pot or griddle. If the gap is too large the hot flue gases mostly stay in the middle of the channel and do not pass their heat to the desired cooking surface. If the gaps are too small, the draft diminishes, causing the fire to be cooler, the emissions to go up, and less heat to enter the pot. The two most important factors for getting large amounts of heat into a pot are:

- Keep the flue gases that touch the pot as hot as possible; and,

- Force the hot gases to scrape against the surface quickly, not slowly.

Air does not hold much heat. Faster hot flue gases scraping against the pot or griddle will transfer much more heat than slow moving cooler air. The size of the channel could be estimated by keeping the cross sectional area constant throughout the stove. This will achieve through systematic design and modeling.

Rate of combustion: the rate of gas production depends on the amount of primary air admitted to the bottom combustion chamber. For this reason it is very important to design a tight sealing valve on the bottom which permits a wide range of air adjustments and a means to control rate of combustion.

\section{Standard House Hold Gasifier Stove Design}

Energy demand Determination: Considering seven family members and "the traditional Ethiopian Derowote" as it is the most energy intensive food type in Ethiopia, to cook within one hour. A maximum of $10302.1 \mathrm{Kcal} / \mathrm{hr}$ required at house hold level needed.

Energy input determination: using the maximum energy required to cook "Derowote" $(10302.1 \mathrm{Kcal} / \mathrm{hr})$ and assuming the new gasifier stove will have an overall efficiency of $39 \%$ (maximum theoretical efficiency) and heating value of eucalyptus Specific fuel consumption of the stove is $6 \mathrm{~kg} / \mathrm{hr}$ or $0.0167 \mathrm{~kg} / \mathrm{min}$ of eucalyptus. Since all types of eucalyptus species grow uniformly throughout Ethiopia, an average calorific value considered in the analysis.

Reactor diameter: The reactor diameter computed using equation 3:3.For Gasifier stove of $6 \mathrm{~kg} / \mathrm{hr}$ fuel consumption, the computed internal diameter of the reaction chamber using an average specific gasification rate of $130 \mathrm{~kg} / \mathrm{m}$-hris $0.24 \mathrm{~m}$.

Height of the reactor: The height of the reactor computed using equation 3:4. Considering the desired operating time of the gasifier stove to be one hour and a biomass density of 250 $\mathrm{kg} / \mathrm{m}^{3}$ the height of the reactor should be $0.52 \mathrm{~m}$.

Insulation material: Even though there are numerous types of well-known stove insulations materials, most of them are not available in the local market, needs special manufacturing technique and knowledge and too expensive to use in house hold gasifier stove manufacturing. As a result of this assessing locally available insulation material is one of the main targets of the project. Based on the investigation the following insulation materials are identified as a potential candidate and presented in table 1 . The insulation materials are selected and prioritized based on their low thermal property, relative availability throughout the country, inexpensive, it doesn't require special knowledge, skill and equipment to manufacture, light weight and acceptable by the community.

Table 1. Relative properties of locally available stove insulation materials ${ }^{[30]}$

\begin{tabular}{llllll}
\hline No & Insulation material & Thermal Conductivity $\mathbf{K}-\mathbf{J} / \mathbf{m}$ & Relative Availability & Relative cost & Workability \\
\hline 1 & Wood ash & $0.092-0.17$ & High & Low & High \\
2 & Clay & $0.15-1.8$ & Medium & Low & High \\
3 & Saw dust & 0.08 & Low & Medium & High \\
4 & Gypsum & 0.09 & Medium & High & Medium \\
6 & Dry River sand & $0.15-0.25$ & Low & Low & High \\
7 & Cement mortar & 1.73 & Low & High & Medium \\
8 & Light weight concrete & $0.1-0.3$ & Low & High & Medium \\
9 & Brick work common & $0.6-1$ & Low & High & Medium \\
10 & Fire clay brick & 1.4 & High & High & Medium \\
11 & Dry soil/earth & 1.5 & Low & High \\
\hline
\end{tabular}


Insulation Thickness Determination: The wall of the reactor and chimney consists of three different materials. The first inner layer is composed of $1 \mathrm{~cm}$ thick clay (the thickness is determined from the local manufacturing experience) that has a thermal conductivity of $1.8 \mathrm{~W} / \mathrm{m}^{\circ} \mathrm{K}$. The second layer is made from wood ash with a thermal conductivity of 0.017 $\mathrm{W} / \mathrm{m}^{\circ} \mathrm{K}$. The exterior layer is made from $2 \mathrm{~mm}$ thick mild steel sheet. The maximum inside temperate of the stove is expected to be $670^{\circ} \mathrm{C}$ and the outside air temperate near to the stove surface is $46^{\circ} \mathrm{c}$ with a convection heat transfer coefficient of $40 \mathrm{~W} / \mathrm{m}^{20} \mathrm{~K}$ and also it is better to neglect the heat lost at the outer surface.

Using economical insulation thickness equation 3:6the thickness of the insulation for all insulation materials listed in table 4.4 including wood ash are less than $3 \mathrm{~cm}$. But for manufacturing simplicity and operator safety it is better to use $3 \mathrm{~cm}$ thick insulation around the combustion chamber. As a result of this $3 \mathrm{~cm}$ thick wood ash used as insulation material around the combustion chamber of the new gasifier stove.

Time to Consume Biomass: For $24 \mathrm{~cm}$ diameter and $52 \mathrm{~cm}$ height reactor biomass gasifire stove operated at a fuel consumption rate of $6 \mathrm{~kg} / \mathrm{hr}$, the time required for a single cycle operation would be 60 minutes. Within this period all the eucalyptus wood fuel will burnt out and the wood gas driven out. Only the charcoal will left and by removing the upper part of the stove safely the charcoal will utilized for same or other cooking purpose.

The Size of Primary Air Inlet: The feedstock enters the reactor undergo combustion with the limited oxygen present in the chamber. To gasify $25.42 \mathrm{gm}$ of wood $24.48 \mathrm{gm}$ of oxygen needed.to create the appropriate thermo-dynamic environment at $2 \mathrm{~m} / \mathrm{s}$ wind speed $13.76 \mathrm{~cm}^{2}$ primary air inlet required

\section{Manufacturing of the Stove}

For the manufacturing of the stove any crafts man shop is sufficient enough. It is manufactured by participating end users and traditional stove makers and has the following basic futures illustrated in the figure 1 below.

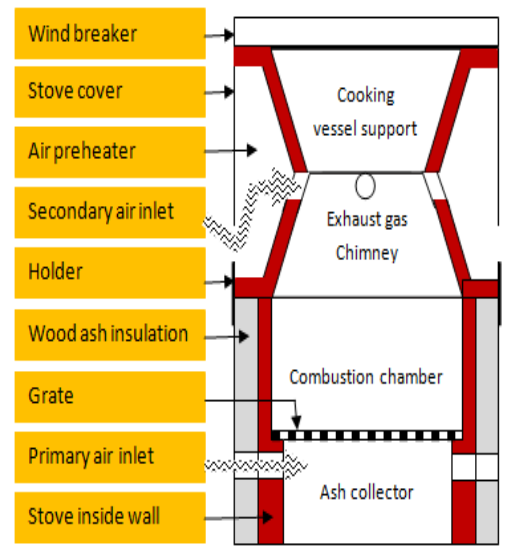

Figure 1. Schematic diagram of the new stove
The stove made of two parts. The upper part (figure 2) and lower part (figure 3) of the stove. This made the stove easy for operation. After the gasification process completed by removing the upper part safely the bottom part used as charcoal stove.

The upper part of the stove serves to oxidize the gas generated as a result of gasification process and serves to transfer the heat generated as a result of secondary oxidation to the cooking vessel (food) efficiently. The upper part (figure 2) includes:

- $1-2 \mathrm{~mm}$ thick sheet metal wind breaker to prevent the diffusion of heat to surrounding prior to transferring the heat to the cooking vessel.

- 1-2mm thick sheet metal Stove cover.

- Air preheater to warm up the secondary air prior to combustion. The preheater utilizes the waste heat energy and helps to improve combustion efficiency and maintaining stove body at low temperature.

- V-shaped cooking vessel support to accommodate different size and shape cooking appliance

- Exhaust gas chimney

- Secondary air inlet

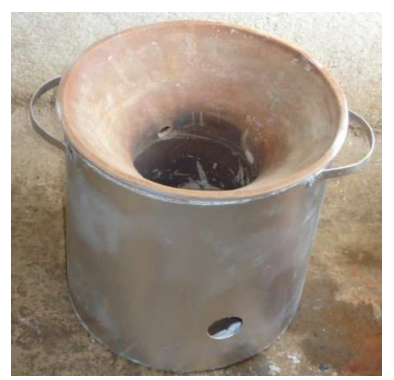

Figure 2. Upper part of the new stove

On the other hand, the lower part of the stove serves as gasifier and charcoal stove. The lower part (figure 3) includes:

- Holder to fix the upper part with the lower one and to prevent side fire.

- Wood ash to pervert heat loss around the combustion chamber

- $2 \mathrm{~cm}$ thick clay Grate having enough primary air inlets used to support wood fuel. The air holes total area enough to primary air inlet and ash fail down but small in size to prevent small sized charcoals.

- Combustion chamber made of clay in which gasification process takes place.

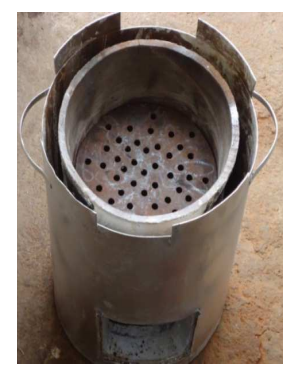

Figure 3. Lower part of the stove 


\section{Experimental Results}

Efficient and complete combustion is a prerequisite of utilizing wood as an environmentally desirable fuel. In addition to a high rate of energy utilization, the combustion process should therefore ensure the complete conversation of wood in to heat and avoid the formation of environmentally undesirable compounds. As shown in the figure 4 below water boiling test carried out to measure and analyze the performance efficiency of the newly designed stove.

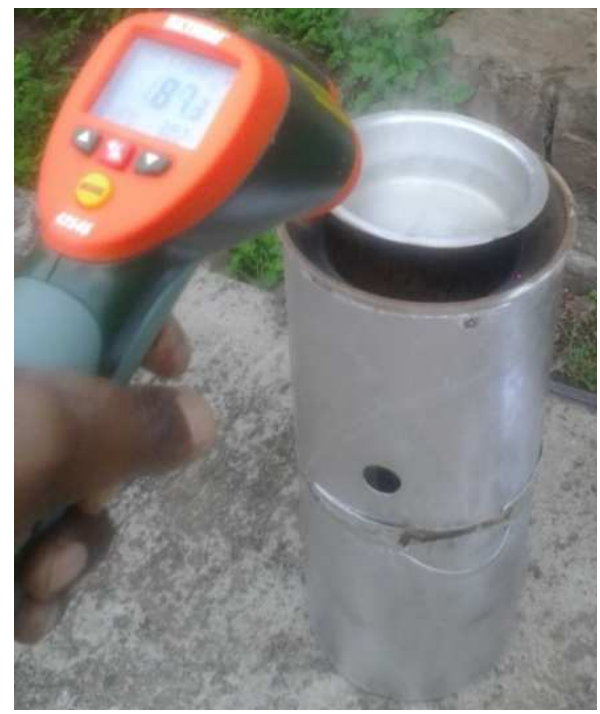

Figure 4. Water boiling test of the new stove

The result obtained from water boiling test summarized in figure 5 below. as shown in the figure 5 below the stove takes an average of $60 \mathrm{~min}$ to boil, have an average specific fuel consumption of $47.04 \mathrm{~g} / \mathrm{min}$, with an average thermal efficiency of $17.2 \%$ and the stove average external body temperature recorded as $46^{\circ} \mathrm{c}$.

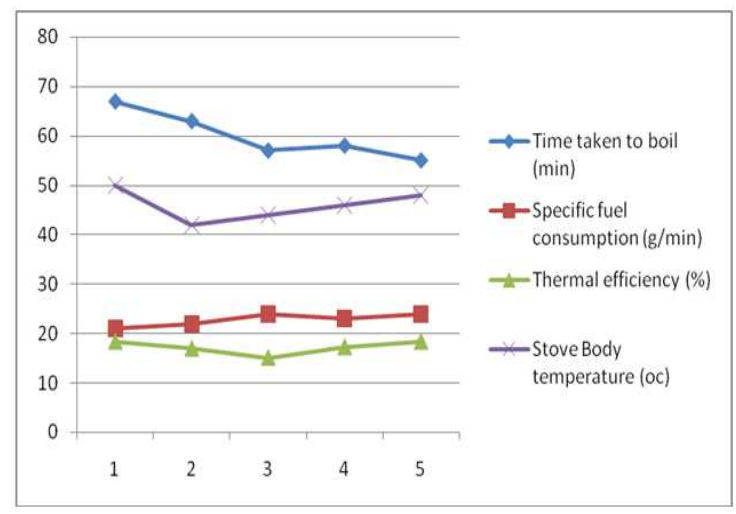

Figure 5. Summary of water boiling test results of the new stove

\section{Improvements}

Compared to the latest and widely used stoves the new design has the following improvements.

1 Use of cheap and locally available materials: the existing house hold stoves made from stain less steel and to some extent from mild steel. But it is expensive and unavailable in rural parts of Ethiopia. The new stove design uses clay as refractory material, ash as insulation material and any hard materials including mild steel or wood as external cover.

2 Construction simplicity: since most gasifier stoves are complicated and made of stainless steel, they require better manufacturing technology. The new design excludes the use of stainless steel and considers the local manufacturing capability of the society. In most crafts man use of Mild steel, wood, ash, saw dust and clay is common practice. As a result it doesn't require new skill and technology. These simplify the manufacturing process of the stove.

3 Use of different size pots: the size of cooking apparatus used depends on the type of food and volume of food to be cooked. As a result the house hold gasifier stoves have to support different size cooking vessels. But most of the stoves available today are designed for single size vessels. If they serve out of the designed size they will exposed for additional heat loss.

4 Control of cooking rate: cooking rate varies from location to location and based on the type of service. But most gasifier stoves of today have no primary air control mechanism to regulate rate of gasification. The new design considers the importance of controlling rate of gasification by controlling primary air inlet. It incorporates primary air controlling mechanism.

5 Elimination of pot support: the current house hold gasifier stoves use additional support structure for the cooking vessels. But the new design eliminates this additional feature. As a result it makes compact and manageable.

6 Elimination of charcoal stove: the champion-2008 stove needs additional charcoal stove to combust the charcoal produced after gasification. But in this stove after gasification process completed the upper part of the stove removed and the lower part of the gasifier serves as charcoal stove.

7 Safety: The existing Updraft gasifier stove outside body temperature as presented by Dr Simon was $93^{\circ} \mathrm{C}$, which can accidentally burn users, so it is recommended to use a handle when moving or handling a hot stove. But the outside temperature of the new gasifier stove was recorded as $46^{\circ} \mathrm{c}$, which is safe to handle during operation.

8 Low production cost: the design Use of locally available raw material and Simplified manufacturing process. As a result the cost of production compared to champion-2008 reduced by more than 8 times. Based on the current material cost it is estimated to be 1106.67birr.

9 Improve thermal efficiency: the efficiency of the new gasifier stove $(17.2 \%)$ is better thanAnila1 (14\%), Sampad (12\%), TLUD (12\%), Anila2 (15\%) and compatible with Everything $(19 \%)^{[11]}$. 


\section{Conclusions}

Energy is one of the most important basic commodities that determine the progress and status as well as the wellbeing of the community. A country's socio-economy cannot show progressive development unless energy is explored, developed, distributed and utilized in an efficient and appropriate way. Based on this facts developing, designing, manufacturing and performance evaluation have been employed in this study.

This study provides the development of enclosed biomass gasifier stove specifically designed for house hold cooking. It provides a mechanism in which household gasifier stoves efficiency and applicability could be maximized. The gasifire reactor has an internal diameter of $24 \mathrm{~cm}$ and an overall dimension of $30.4 \mathrm{~cm}$ diameter by $70 \mathrm{~cm}$ height and a specific fuel consumption of $1.3 \mathrm{~kg} / \mathrm{hr}$. The performance efficiency of the stove was evaluated using water boiling test and a thermal efficiency of $17.2 \%$ was obtained.

The results obtained from this study shows that the gasifier performance and operating conditions are good. So the stove can provides modern energy services for basic needs and productive applications in the areas.

\section{References}

[1] Ethiopian Electric Agency, 2002, Symposium Proceedings of Rural Electrification, Addis Ababa, Ethiopia.
[2] Richard, Wright.T Bernard and Nebel.J, 2002, Environmental Science, to Ward a Sustainable Future, New Delhi, India.

[3] Ethiopian Forestry Action Program (1996)

[4] DestaMaberatu and MulugetaTamire, 2002, Energy in Ethiopia; Status, Challenges and Prospects, Proceedings of Energy Conference 2002, Addis Ababa Ethiopia.

[5] Improved rural woodstoves. October 2003. Ethiopian Rural Energy Development and Promotion Center. BTG biomass technology group BV

[6] Ethiopia Rural Biomass Supply-side Strategy. March 2003. Ethiopian Rural Energy Development and Promotion Center. Biomass Technology Group BTG.BV

[7] W. Gashie, 2005. Factors controlling Households Energy Use: Implication for the Conservation of the Environment. Addis Ababa University, Ethiopia:

[8] Reddy, A.K.N, R.H Williams, 1997, New Opportunity in Energy Demand, Supply and Systems in energy After RioProspective and challenges UNDP

[9] YohannesShiferawSherka, June, 2011; Design and Performance Evaluation of Biomass Gasifier Stove, Addis Ababa University, Addis Ababa

[10] Alexis T. Belonio, 2005, RICE HUSK GAS STOVE Hand BOOK, APPROPRIATE TECHNOLOGY CENTER, Iloilo City, Philippines,

[11] Dr Simon Shackley: Biochar stoves, an innovative studies perspective; UK Biochar Research (UKBRC), school of Geosciences, Univrsity of Edinburgh. $8^{\text {th }}$ April 2011. 